\title{
FENOMENOLOGÍA
}

\section{DIARIO DE CAMPO EN UNA UNIDAD DE PSIQUIATRÍA Realizado durante las prácticas clínicas de Enfermería psiquiátrica}

\author{
FIELD NOTES IN A PSYCHIATRIC UNIT \\ Written during clinical practice in psychiatric nursing \\ DIÁRIO DE CAMPO EM UMA UNIDADE PSIQUIÁTRICA.
}

Realizado durante as práticas clínicas de enfermagem psiquiátrica

Gema Zamorano Orellana

Alumna de $3^{\circ}$ de Enfermería

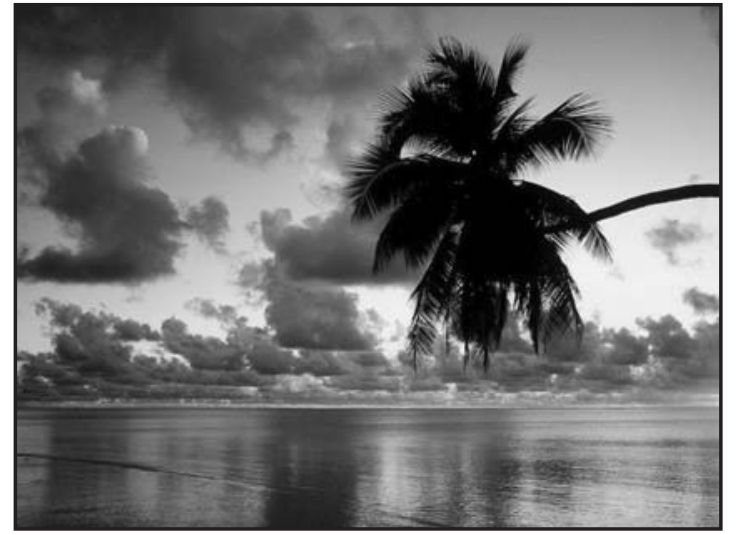

¿Una decisión muy arriesgada?

Es el primer día de prácticas, las últimas ya de la carrera, de esta etapa que ha pasado vertiginosamente rápido. Pese a la experiencia de años anteriores, aún hoy, me siguen temblando las piernas. Voy a hacer este primer módulo en la unidad de psiquiatría. Sé que mi labor ahí no tendrá nada que ver con la de mis otros compañeros que están en unidades medico-quirúrgicas, por ejemplo. Obviamente, estoy nerviosa y por mi cabeza pasan muchas suposiciones de lo que supondrá mi estancia allí.

Por fin llego, me presentan, me presento. El color lavanda de las paredes de la unidad me relaja algo, me gusta el ambiente a priori. Veo a varias pacientes femeninas recorriendo el pasillo una y otra vez. Intento acoplarme cuanto antes a la unidad haciendo preguntas al enfermero, leyendo historias,... pero nada, toda información que entra, sale igual, no soy capaz de concentrarme. Me siento totalmente extraña, me apetece mucho conocer a los pacientes, pero me es imposible, puesto que no tengo confianza aún con el entorno.

Palpo un clima de silencio y canales de comunicación cerrados entre personal sanitario y pacientes. Coloquialmente: "cada uno va a la suya". Comienzo a sentirme mal al ver esa pasividad en el entorno, sobre todo, porque me interesa muchísimo conocer a los pacientes como ya he dicho. Gana mi timidez por dos razones: primero, que no quiero dármelas de "sabelotodo", y segundo, que temo cometer algún tipo de error con los pacientes y que me culpen mis superiores.

Posteriormente, al terminar de entrevistar a un paciente que acaba de ingresar por una alteración de la conducta, también me he sentido defraudada conmigo misma. Me he cerciorado de cuán difícil es establecer una comunicación asertiva, empática, con feedback, donde poder comenzar a conocer al paciente, y que él comience a conocerte a ti, donde mostrarle que puede confiar en ti, que tú le escuchas abierta y honestamente. El nerviosismo y la inexperiencia se han apoderado de mí. He salido de la habitación con la mirada perdida y desconcertada.

Intento poner mi sentido de la adaptación al cien por cien, pero no responde. Soy franca conmi- 
go misma, es el primer día, es un mundo asistencial muy distinto de lo que conozco, y por lo tanto, soy inexperta. No puedo pretender saber hacerlo todo perfectamente y respondiendo a las expectativas que me había creado, quizá algo irrealistas.

Durante la mañana, me comentan que muchos de estos pacientes son manipuladores, pocas veces agresivos, maleducados, etc, pero lo que veo es que tienen una necesidad inmensa de comunicarse, de relacionarse, y no he visto esa relación profesional enfermero basada en la comunicación con sus pacientes. ¿Tan difícil es?

Reitero, necesito conocer a esas personas, que me hablen, que se comuniquen conmigo,... asumo esa responsabilidad. No quiero parapetarme en el control de enfermería todos los días, como si estuviera hacinada ahí, como si tuviera miedo a esas personas, cuando lo que realmente me da miedo es adoptar la actitud de barrera.

Además me siento apenada, porque tengo la sensación de que el enfermero de hoy no me escuchaba, y por lo tanto, el cúmulo de desconocimiento, nuevo entorno, etc, me ha sobrepasado al llegar a casa, haciéndome sentir confusa, dudando incluso de la decisión que tomé al elegir esta unidad para hacer mis prácticas.

\section{Un soplo de aire fresco}

Durante la mañana todo ha ido progresando hacia el extremo opuesto de lo que ayer sentí. Se debe, esencialmente, a la presencia de una enfermera que se está especializando en salud mental y se encuentra haciendo prácticas en la unidad en la que me encuentro. Desde el momento en que la he saludado, he tenido la simple impresión de que ya no estaba sola, y eso que no había mantenido ninguna conversación con ella aún. Esta nueva compañera del EIR, que me ha hecho sentir su compañera de equipo también, me ha dado la capacidad o el impulso para poder ir a hablar con los pacientes, tanto, que algunos ya se conocen mi nombre, me hablan de los libros o cosas que les gusta hacer, etc, cosas banales a priori, pero almenos es un comienzo. Yo les he preguntado y he contactado algo más con ellos, en comparación con el día de ayer.

Al hacerle la entrevista a una paciente que ingresaba por ideas autolíticas, su debilidad y su ternura me han cautivado, y he sentido tal comodidad en frente de y con ella, que he estado más espontánea y he realizado preguntas más coherentes con lo aprendido en la teoría, que en comparación con la entrevista fallida, o por lo menos, tan poco correcta que realicé ayer.

A diferencia de ayer, hoy me he sentido orgullosa del pequeño progreso que he realizado. Me he sentido un poco menos lejana con las personas que ahí están ingresadas, y algo que me ha sorprendido gratamente, he creído empatizar- no verbalmentecon la pareja sentimental de la paciente que hoy ha ingresado, que además es su cuidador. He visto reflejado en su mirada, sus gestos, esa tristeza de ver a la persona que quieres en un estado de inestabilidad emocional visible e irreconocible.

El día de hoy, sin duda alguna, ha sido un soplo de aire fresco.

\section{Diciendo adiós}

Para mí, hoy ha sido un día melancólico. Afuera un día gris, frío y lluvioso. Adentro, una mujer adulta - indigente, dependiente de sustancias y que hace más de un mes ingresó por ideas autolíticas- es dada alta. Es la mujer con la que más he hablado en lo que llevo de estancia aquí. Es admirable lo amable, educada, sonriente y dulce que es, a pesar de no haber llevado una vida fácil, y a pesar de estar sola y ser rechazada por sus propios hijos. En lo que llevaba ingresada, cero visitas, cero llamadas. Sólo la acompañaba su libro, sus gafas, su pintalabios y su vestimenta.

Se viste, se prepara para salir de una estancia cómoda, donde ha podido saber de nuevo qué es dormir de verdad en un colchón, comer cada día caliente, estar cuidada, aseada, resguardada en un lugar seguro. Y de repente, como el pajarito que deja su nido, se va despidiéndose de nosotras, con esa sonrisa que la caracteriza, pero con una mirada tremendamente triste y desubicada, como preguntándose: ¿Qué va a ser de mí ahora? ¿A dónde voy exactamente?

Se le ha asignado un albergue a donde debe ir, - me pregunto ahora si ha llegado - cruza la puerta acristalada que la separa del mundo exterior, se para en el recibidor a ponerse sus collares, y dice adiós con la mano y su sonrisa siempre presente. No sé porqué, pero ¡qué orgullosa estoy de esa mujer!, de lo fuerte qué es a pesar de sus debilidades. Nuevamente, nos dice adiós con su mano y su sonrisa, mientras le respondo desde detrás de la 
puerta acristalada. Dice adiós a otra época más de su vida. Ella no lo sabe, pero le deseo lo mejor.

Yo por mi parte, digo "adiós" a ese primer día aquí, donde tanta negatividad me invadió, y digo "hola" a mirar las cosas positivas que tiene este lugar, y sobre todo, a las personas que habitan en él.

\section{La experiencia de los años}

En el turno de hoy, he tenido la suerte de contar con un enfermero que tiene una larga trayectoria en la asistencia psiquiátrica. Me ha transmitido su saber acumulado procedente de la experiencia, su respeto y también admiración por este campo de la enfermería. He agradecido mucho su interés por enseñarnos, -tanto a mí como a la enfermera residente-, la técnica de la contención mecánica, eso sí, haciendo hincapié tanto en la esfera biopsicosocial de la persona a la que contenemos, como en la familiar, cuando ese paciente es visto por sus allegados.

Nos ha transmitido dos ideas fundamentales respecto al poder que tiene el enfermero cuando decide contener físicamente a un paciente. La primera idea se resume en la siguiente frase: "el poder estriba en que tenemos ese poder para evitar utilizarlo". Frase que creo que significa mucho en relación a la segunda idea: "a los pacientes no se les amenaza con aplicarles la contención física, eso es una falta de profesionalidad y una estupidez, sino que siempre y en cualquier situación, hay que aplicar preferentemente, la humana contención verbal".

Por supuesto, no solo nos ha dado una clase teórico-práctica sobre contención mecánica, sino que también se ha interesado voluntariamente por enseñarnos y hacernos aprender. Creo que eso dice mucho de una persona y de cómo trabaja, a pesar de su seriedad y gesto concentrado y casi, inexpresivo. Claro que prefiero esto, a una simpatía a borbotones y sin franqueza.

En resumen, hoy he sentido que me evaluaban desde las críticas constructivas, y por ello, he reanudado mi capacidad de atención tanto, que he percibido que nada mejor que la exigencia desde la empatía para aprender.

\section{Después de la tormenta viene la calma}

Lo más significativo del día de hoy ha sido ver cómo una paciente con trastorno de personalidad se disculpaba ante mí y mi compañera, por haber gritado y llorado tras la cita con su psiquiatra, el cual le había comentado que tenía que seguir ingresada. En el momento que ella ha sabido de esa información, se ha sentido engañada y manipulada. Sus palabras textuales eran: "me siento en una prisión, quiero respirar aire fresco, estoy harta de estar aquí". Mientras expresaba todo su llanto, hemos estado a su lado intentando calmar y aliviar, o simplemente escuchar a una persona que tiene un deseo ferviente de no ver las cuatro paredes que la rodean día tras día desde los dos meses que lleva en la unidad. Estaba desesperada, tenía que desahogarse. No quiero poner en duda su llanto, si fue teatro o no, creo que la desesperación como yo la he visto esta mañana, no se puede disimular tan bien.

Como ya he dicho, luego se ha calmado. Hemos comenzado a hablar con ella sobre sus gustos literarios y musicales, y se ha ofrecido voluntariamente a leernos un poema que ella mismo había escrito. Un poema sobre el enamoramiento.

Mientras lo leía, he pensado que cómo una persona con tanto potencial intelectual - fue una alumna brillante en el instituto según su historia clínica -, estaba ahora abocada a la soledad de una habitación de un hospital rodeada únicamente de sus libros, su música, y su poema. No podía evitar sonreír al oírla citar dicho poema.

La verdad que sentí pena por ella en ese momento. Pues en cierto modo, lo que podría haber sido su proyecto de vida, está momentáneamente desvanecido, y su capacidad intelectual desaprovechada.

Respecto a esta paciente, me molesta que la enfermera mediante una orden implícita me diga que no debería acercarme a ella. Hago caso omiso. Si esa persona me resulta tranquila y dentro de lo que cabe, serena, me es imposible obviarla.

Incluso, no me parece tan desagradable ni tan esperpéntico que se ponga a gritar y a llorar desesperanzada en medio del pasillo, me parece algo natural y humano teniendo en cuenta su diagnóstico.

Como digo, la energía negativa mejor sacarla hacia el exterior - no hacia nadie en concreto antes que contenerla. Es el único modo de que la tormenta dé paso a la calma interior.

\section{En medio de la incertidumbre}

Me gusta la planta y los pacientes y sus peculiaridades. Hablo con mis compañeros sobre la 
Unidad mientras intento borrarles ciertos prejuicios sobre los enfermos mentales. He adoptado tal solidaridad con este tipo de pacientes, que me molesta oír ciertos juicios de valor basados en el desconocimiento más que nada. Me molesta incluso que mis compañeros sólo hablen de técnicas. Me he dado cuenta que evito las técnicas, que prefiero dedicarme a otras labores que creo que una enfermera tiene que desarrollar. Siento deseos de terminar mi etapa estudiantil. Siento ganas de ser la enfermera que yo deseo ser, sin estar sometida a la forma de trabajar de otros. A mi compañera del EIR también la veo cohibida en sus actos, ya que se lo pregunté y me contestó afirmativamente.

Observo la madurez de otras enfermeras y me digo: prefiero que pasen 25 años de una vez, y tener conocimientos bien sedimentados tanto a nivel profesional como personal, a estar ahora sumergida en esta incertidumbre que parece no cesar. La seguridad de la experiencia es algo brillante. O sea, supongo que el malestar que hoy me invade es fruto de sentir que simplemente aún soy una estudiante de enfermería.

Hoy me sentía realmente desmotivada. Como sentada en la orilla de una playa de una isla solitaria contemplando el atardecer, con la incertidumbre de no saber porqué me encuentro aquí y sintiendo que no me puedo cambiar de postura, que sólo puedo contemplar, mientras los atardeceres se van sucediendo día tras día.

\section{El séquito vigilante}

Eran las once y media de la mañana. De repente llegan a la unidad un séquito de guardias de seguridad rodeando a un hombre alto, que parece desorientado, con la expresión inocente, pero nervioso. Se resiste a entrar a la habitación, y de repente todo el séquito se avalancha innecesariamente sobre él, sin ni siquiera hablarle antes. Estaban plenamente decididos a aplicarle la contención mecánica, a este hombre, que ni siquiera ha gritado o alzado la voz, que simplemente está desubicado y confuso.

Menos mal que se han ido pronto. El enfermero y yo hemos podido hablar tranquilamente con el paciente, explicarle que no vamos a trabarle (no me gusta esta expresión), ayudarle a vestirse y a asearse, ayudarle a relajarse y conciliar el sueño en medio del caos que seguro ha sentido en esos instantes.
Ha sufrido recientemente un brote psicótico. Casi logra salir del hospital, porque en otra unidad le practicaron, no solo una contención mecánica innecesaria, sino que además una contención mal aplicada y sin fundamento, que fue la razón por la que consiguió escapar de la unidad en la que se encontraba.

Me apena tanto observar estas cosas a mi alrededor. ¿A dónde y cuándo expulsamos de una patada inconsciente nuestra actitud y comportamientos más humanos? Sin embargo, en estos momentos perdura más en mis pensamientos el hecho de que gracias a nuestra intervención verbal, franca $\mathrm{y}$ honesta, ese hombre seguía calmado y sereno en su habitación, observando por la ventana con gesto nostálgico, el exterior, ese del que desgraciadamente está privado momentáneamente.

Tal vez, yo también me muestre algo esperpéntica o sentimental en lo que voy a decir ahora, pero: cada una de las personas que ingresan en la unidad generan en mí una necesidad de hacer uso de una dinámica de los cuidados más maternal que estrictamente sanitaria, y eso, es lo que más me llena en estos momentos.

\section{El laúd que se derrumba}

Hoy he conocido a un hombre con una trayectoria académica importante. Locuaz verborrea, manifestaba sus conocimientos cada vez que respondía a mis preguntas. Era explícito y detallista en sus palabras. Me ha costado centrar la atención en su discurso, tal vez algo monótono en ciertas ocasiones. Me he sentido algo abrumada también ante dicha logorrea. Consigo centrar mi atención. No dar cabidas a pensamientos como "no consigo entender lo que dice... porqué me contará esto ahora, qué digo...". Estoy descubriendo que el miedo a hacer entrevistas se está fulminando poco a poco. Me gusta hablar a solas con estas personas.

Presentaba un trastorno esquizoafectivo de base. Me he cerciorado una vez más de lo que supone hablar con alguien, porque sin ese canal o válvula de escape que he sido yo esta mañana al escucharle, esa persona no hubiera podido descargar la tensión interior que significa ser el cuidador de una madre que padece Esquizofrenia y Alzheimer.

Sus palabras eran "me encuentro sobresaturado, y mi tía me reprocha que todo lo hago mal". He 


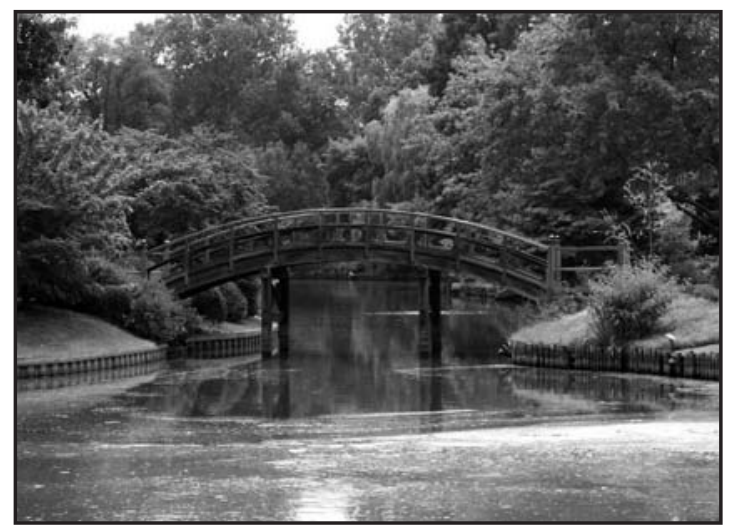

aquí un gran estigma social representado hacia este colectivo. Me he cerciorado de lo voluntarioso y competente que es este hombre al encargarse de su madre, y además, encargarse también de los gastos de una residencia donde se encuentra su padre, enfermo de cáncer terminal. Y se supone ¿que todo lo hace mal?

\section{Las preguntas sin respuestas}

Me sigue costando ver a mi alrededor cómo a una persona en estado de psicosis con su desorientación correspondiente, se la despoja de su ropa rápidamente, se le pone el pijama hospitalario, se le quita el collar de su novio al que llama reiteradamente, se le tumba en la cama, se le sujeta con fuerza, se le suprimen la amplitud de sus movimientos con correas y demás sujeciones mecánicas. Pienso otra vez, que no era necesario, luego pienso que sí, porque estaba en riesgo su propia seguridad.

Aún así, me sigo sintiendo impactada ante estas escenas. No se asemejan a la brutalidad para nada, pero ante mis ojos lo son. Me imagino a mi misma en su situación. No estoy acostumbrada a que hagan por mí lo que yo hago diariamente de forma casi mecánica. Sobre todo porque forma parte de mi esfera privada e íntima.

El hecho de que cambiasen de ropa a la paciente en contra de su voluntad (a pesar de su estado Psicótico) y que mientras tanto estuviera exclamando qué hacían, que porqué, que le daba vergüenza, etc, ha hecho que para mí, ver eso, significara algo que atenta contra la dignidad de uno.

Y luego. Luego estaba tumbada, con una expresión asustada, no parpadeaba, con una flexibilidad cérea visible. Se encontraba como petrificada. Al verla así he sentido algo de horror. Quería despertarla de ese estado, era como si estuviera ahogándose con el aire y no pudiese comunicármelo. Qué sensación. Impactante de nuevo.

Lo peor de todo es que ignoraba inconscientemente a mis preguntas, y entonces, la sentía más lejos aún, como si corriera detrás de ella para sacarla del túnel, y el suelo resbaladizo no me dejase avanzar para socorrerla de su desorientación.

Increíble lo que he visto y sentido hoy. Cuando la comunicación con otro ser humano se hace imposible. He sentido angustia.

Le he dicho mi nombre, ¿se habrá guardado en sus recuerdos? Aún siento esa ausencia que me ha hecho percibir. La miraba fijamente, me miraba fijamente. He sentido incluso que me transportaba a esa esfera de ausencia sin ruido. Ahora que lo pienso, perfectamente se podría decir que se estaba comunicando con los ojos, y eso lo que me dice, es que ella también estaba asustada y temerosa. Qué gran conexión la de las miradas entonces. Siempre he pensado que la comunicación no verbal es bella y mucho más importante que las palabras en boca. ¿Cómo si no, se explica esta situación que he experimentado?

\section{La respuesta a las lágrimas}

La mujer que ha ingresado hoy, por síndrome ansioso-depresivo, me ha vuelto a recordar lo importante que es saber llevar a la práctica la escucha activa, poniendo los cinco sentidos integrados, empatizando con esa persona.

Realizándole la entrevista, se encontraba desubicada, con la mirada perdida y triste,... me decía que se quería ir, que no necesitaba estar ingresada, ha comenzado a sollozar y seguidamente a llorar. Yo estaba sola con ella, le he puesto una mano sobre el brazo, y lo único que he acertado a decir en tono calmado y afable, es: "si los doctores han decidido que ahora has de pasar unos días aquí, es porque desean tu bienestar, y para conseguirlo de nuevo es necesario que estés con nosotros “. Su respuesta: “ya, pero...". Ha dejado de llorar, pero seguía murmurando que se quería ir.

Como no sabía qué más hablar con ella, no encontraba palabras adecuadas, he optado por decirle que me encontraba a su disposición para cuando lo quisiera. 
$\mathrm{Mm}, . .$. no me siento muy satisfecha con este intento de escucha activa. Creo que ni siquiera la he dejado hablar o expresarse, y mucho menos he profundizado en porqué quería irse.

Siento que debería haber una consulta de enfermería dentro de la unidad especialmente dedicada para hacer las entrevistas a los ingresos, porque en las habitaciones, entran y salen los compañeros de habitación, entra la auxiliar, etc, todo son interrupciones, y creo que yo también me sentiría más cómoda y tranquila para poder ir conversando con la paciente practicando la escucha activa, que tengo clarísimo, que hoy no he realizado.

\section{La simpática persuasión}

Hoy he conseguido que la paciente tímida y reservada a la que ayer entrevisté, salga de la habitación, que no esté hacinada ahí. Solo lo he conseguido durante unos minutos, pero algo es algo. No he conseguido una conversación muy fluida por su parte, creo que a veces hablo demasiado y dejo hablar poco. Creo que me ha ocurrido con esta señora. Pero su inquietud de manos, su mirada, repito tímida, su ausencia verbal me hacían sentir incómoda. Ahora pienso que a lo mejor era innecesario mostrarle mi apoyo para que saliera de su habitación. Que tal vez no necesitaba mi compañía. Me he sentido que tal vez la estaba forzando. Pero desde ayer que la valoré por primera vez y avisté esa inseguridad palpable en el más mínimo de sus gestos, pues sentí el impulso de ayudarla a relacionarse más.

Pues la verdad es que creo que por un lado he hecho bien, y por otro me siento una total persuasiva, siento que he forzado esa situación. Esto último me pesa más en estos momentos. Sobretodo porque no he visto una respuesta verbal de ella mucho más intensa o enérgica de lo que me esperaba.

Ahora me viene a mi mente una frase que me dijo un enfermero: "en los primeros contactos, no pretendas que te den su confianza". Exacto. He sido una confiada en toda regla. ¡Pero si ingresó ayer, y ya la estoy tratando como si la conociera y me conociese más profundamente! De nuevo el "pseudopoder" de la bata blanca que nos hace creer que somos omnipotentes y con capacidad para conseguir cualquier cosa. Almenos me queda la experiencia, de ver cómo no quiero volver a comportarme.
A veces siento que mi tono de voz o mi comunicación verbal con estos pacientes es más dada a la simpatía que a la empatía, más dada al trato amistoso que al trato esencial de enfermera cuidadora, y me ofende y molesta dicho comportamiento mío, porque no me veo natural o con la suficiente experiencia laboral en este campo.

\section{La cara delirante de la timidez}

Nuevo aprendizaje para el día de hoy, que ha terminado de nuevo con el enojo personal momentáneo que supone ver cómo, hasta llegar a poseer sabiduría parcial en las habilidades psicológicas sobre todo en el trato con pacientes que sufren de psicosis- todavía he de dar unos cientos y miles de resbalones en el barro - aún no fangoso- de la práctica asistencial.

La misma paciente del día anterior. Lo sucedido se resume de la siguiente manera: La veo salir de la habitación, yo en la salita común con los pacientes, sentada con mi compañera del EIR. Se va acercando discretamente hacia mi posición; se sienta a mi lado; se me acerca cada vez más; comienzo a extrañarme; ella repentinamente se levanta, permanece a mi lado pero no para de golpear levemente la mesa con sus dedos mientras mira como abstraída y ligeramente - sin yo haberme percatado- a todo el mundo que hay en la sala, esto lo hace repetidamente.

La EIR y yo observamos que algo no anda bien, lo ubicamos como simple nerviosismo - muy a nuestro pesar posterior -, así que le insistimos en acompañarla a su habitación por si quiere hablar o contarnos cómo se siente en el día de hoy.

Al principio, respuestas coherentes que tardan en proyectarse al exterior, y luego respuestas literales como: ¿me estáis mintiendo? ¿Sois sinceras conmigo? El demonio tiene la culpa de todo. Respuestas sin razón aparente.

Ideas parecidas repitiéndose una y otra vez. La mirada de la EIR y la mía convergen, y se dicen, mejor marcharnos con: mire le vemos muy intranquila... ya le hemos dicho que no le mentimos ni le mentiremos... debemos seguir con nuestras tareas... si necesita algo más, nos llama.

Muy acertada no parece ser nuestra despedida.

Al rato sale de su habitación que está cerca del control de enfermería, se queda paralizada en la puerta de su habitación, nos mira con cara de des- 
confianza, nos llama discretamente y nos sigue insistiendo en que le mentimos, optamos por dejarle claro que no es así, se acerca al control, nos observa, y nos sentimos espiadas. Yo a la vez me siento culpable, mi compañera comienza a ponerse nerviosa y se lo comunica a la enfermera responsable de la planta. Nos dice que la obviemos. Y todavía no le hemos puesto nombre a lo que ha pasado.

Además de hacerme sentir culpable, el comportamiento de la paciente me está inquietando y me está diciendo que teníamos que haber sido más avispadas y haber reconocido con avidez y agilidad, el cuadro delirante que la paciente comenzó a mostrar desde que se sentó a mi lado en la salita.

La psiquiatra ya nos ha advertido de su nuevo diagnóstico. Síndrome ansioso-depresivo psicótico. Desde luego, un nuevo aprendizaje sin duda. Pero yo personalmente me he sentido culpable. Si yo ayer no hubiera comenzado esa relación personal aún en fase de "precrecimiento", ¿hoy se habría acercado a mí y hubiera pasado todo lo que ha acontecido luego? No sé la respuesta. Pero tengo claro que el trato simpático - porque no fue nada empático - ha traicionado a mi mismidad.

En resumen y de nuevo, la inexperiencia es la que me hace naufragar en estos caudales de una manera inevitable, pero creo que fructífera para el futuro. Dado que no puedo cambiar el curso y efectos de esta inexperiencia, lo único que me queda es ir sacando el jugo pragmático al fruto del aprendizaje, siendo consciente de estos cambios, que en futuras situaciones similares me puedan ayudar a afrontarlas de una manera más saludable a nivel emocional y profesional.

\section{El recuerdo de lo que podemos llegar a ser}

La psiquiatra, a la que ayer comentamos el episodio delirante de la paciente con síndrome ansioso-depresivo psicótico, ha venido hoy a hablar con nosotras. Según ella, no tuvimos que iniciar ningún tipo de conversación con la paciente, pues acrecentábamos su delirio. De acuerdo, hasta ahí reconozco que tiene razón, totalmente. Pero luego ha dicho textualmente: "no estáis capacitadas para la labor terapéutica en la comunicación con el enfermo mental, y mucho menos, si este está en un estado de delirio". Esta frase la ha pronunciado con un tono de voz claro, franco y honesto, como haciéndonos creer que era por nuestro bien no inmiscuir- nos tan profundamente en la asistencia a este tipo de enfermos, claro, pero al mismo tiempo nos estaba inculcando la idea oculta de que enfermería no debe sobrepasar de la mera observación, toma de constantes, etc.

Yo he pensado de nuevo: estoy de acuerdo en el fallo de comportamiento que ayer propiciamos, pero eso no quiere decir que dentro de unos años o cuando nuestro bagaje con pacientes psiquiátricos sea más extenso y experimentado, no podamos desarrollar una labor profesional enfermera basada más en la relación terapéutica de comunicación, y que enfermería no se dedique solo y exclusivamente a administrar medicamentos en un vasito, entre otras cosas meramente técnicas.

Luego he seguido reflexionando y me he dicho: es normal que ésta psiquiatra piense que enfermería no esta capacitada para la comunicación terapéutica, si lo único que ve en nuestros relevos es "La paciente permanece tranquila y correcta todo el día. Duerme y toma la medicación”. Una frase que se usa generalizadamente para todo aquel paciente que ni grita, ni se moviliza, ni intenta nada extraño, etc, es decir, es la oración típica y tópica, la oración que todos usan, la oración que no demuestra lo que se ha trabajado realmente, y por lo tanto, revela que nuestro trabajo no se ejecuta con totalidad, tanto en calidad como en cantidad, y por lo tanto el producto es un trabajo pobre, alejado de una profesionalidad más elaborada y nunca mejor dicho, trabajada.

Claro, así ya puedo entender la postura de la psiquiatra. Es lo que ve, no estoy intentándola apoyar en lo que dice, pero puedo entender su planteamiento. No se fía, tal vez, de nuestras competencias o verdadera profesionalidad, porque no las ve, quizá es escéptica y empirista subjetivamente en este sentido.

Sé que ejercer esta profesión sin interés y apatía me dañaría, y no sabría cuidar realmente a los demás, así pues intento hacerlo lo mejor posible intentando no olvidar la parte de arte esencial que tiene la enfermería, e intentando también no caer en el optimismo y esperanza desmesurados, pero almenos teniendo ideas de cómo me gusta a mí llevar a cabo esta profesión.

\section{El caudal de la comunicación}

Cuando esa persona que tienes delante, como paciente, te confiesa: "soy una alcohólica perdida 


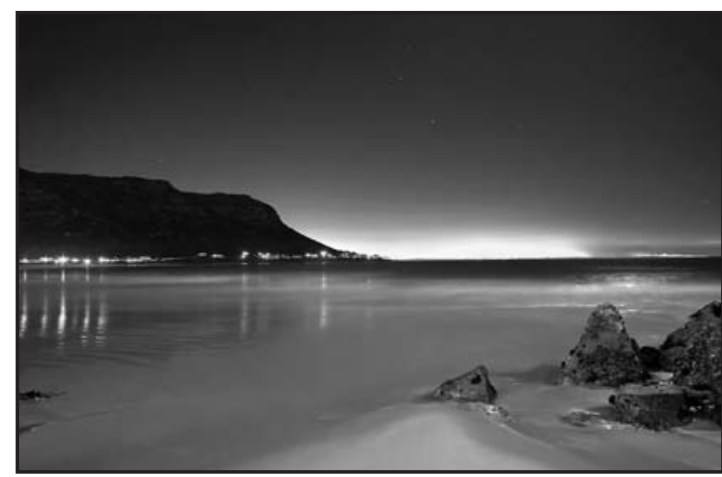

desde que murió mi madre... la gente del barrio me llama loca con sus miradas...he optado por no salir de casa...refugiarme en ella... con el único apoyo de algunos de mis vecinos". Aquí la humanidad misma, lo que es el ser humano más esencial se te desvela cara a cara. Cuesta asimilar lo que te está relatando con franqueza y tono de voz grave, y serio, pero a la vez triste, desesperanzado. En estos momentos, adopto espontáneamente el mismo tono que ella, le hago saber que la gente es muy injusta, que se habrá sentido muy sola al ver como los que la rodean se alejan sin conocerla antes. Me afirma que es así, mientras asiente con la cabeza y cierra los ojos, los vuelve a abrir y vuelve a mirarme. Comienza a explicarme cómo se siente, va hilando temas, consigo no desviar mi atención. Me estoy sintiendo muy cómoda con esta entrevista que voy elaborando, con este flujo de mensajes, entre esa mujer y yo.

Me estoy quedando perpleja de lo fluida y abierta que va siendo la conversación. Además, sin conocer de nada a esta paciente, he pedido expresamente a la enfermera que quería realizarle yo la valoración, y obviamente a solas.

Me he sentido capaz, con fuerza, con habilidad para hablar franca y honestamente, sin dar lugar a malos entendidos, suposiciones, y lo que más me ha encantado, que yo he abierto solo la puerta, y ella ha ido autoexplorando lo que sentía, mientras yo solo reafirmaba de vez en cuando y guiaba muy sutilmente. Quizá no lo haya hecho perfecto, pero he salido de la habitación con muy buen sabor de boca, como se dice.

Ha sido un espacio de tiempo, sin prisas pero sin pausas, relajado, calmado, tranquilo, sincero, armónico quizá. Me he sentido muy coherente con mi expresión, tono de voz, gestos, palabras.
Me pregunto si ha sido la propia paciente la que me ha facilitado todo ello, o que voy adquiriendo destreza. Supongo que un poco de las dos. Es una sorpresa para mí haber vivido esto hoy.

Creo, sin lugar a dudas, que he traspasado esa barrera de la que hablaba, la barrera con los pacientes, la que me impedía acercarme a ellos. Ha sido como recibir una dosis de motivación titánica, eso sí, sin olvidarme de la realidad e intentado no magnificar hasta el exceso la situación que hoy me ha tocado protagonizar junto con esta persona.

Otra cuestión que también me ha gustado mucho, es que no he sentido lástima o pena por ella, sino que me he posicionado en su favor, no la he culpabilizado ni prejuzgado, simplemente he sentido la necesidad de hablar con ella, más que hacer una pura valoración o entrevista rutinaria.

\section{Breve parada en la estación de la infancia}

Entramos como cada día a curarle las heridas, a realizarle su electrocardiograma de control, a preguntarle si se siente mareado, si tiene apetito... pero nunca le preguntamos ¿Cómo te sientes? ¿En qué piensas? ¿Qué te apetece? No franqueamos la línea que en un principio creía que él delimitaba, somos nosotras quienes acotamos, que por miedo a sus posibles e imprevisibles reacciones comportamentales, intentamos ceñirnos solo y exclusivamente a las rutinas no inhumanas, pero sí mecánicas y casi cebadas de cobardía y temor, como ya he dicho, a posibles malinterpretaciones que este paciente diagnosticado de esquizofrenia paranoide, pueda construir en su mente acerca de lo que nosotras podamos decir. Ahora me doy cuenta, que las que más malinterpretan y "antesuponen" somos nosotras. Y me doy cuenta, porque hoy ha sido distinto. Nos ha sonreído, él nos ha hecho reír después de tanto tiempo en fase casi ausente.

Él ha recordado su infancia, ha hablado por primera vez de sí mismo en primera persona, ha hablado de él y de su vida, esa que parecía no tener, pero la tiene, claro que la tiene. De repente, él, ha despertado de su letargo, ha sonreído, ha hablado por iniciativa propia, y no meramente respondiendo a nuestras preguntas de tono tímido y cobarde. Un gran progreso.

Como me temía, esta fase ha sido breve, pero repito, muy significativa. Después del desayuno y de dormir durante el resto de la mañana, ha des- 
pertado de nuevo, callado, sigiloso, cabizbajo y con el habitual ceño fruncido.

$\mathrm{Su}$ familia le hizo exiliarse forzosamente de su núcleo, sin tener tampoco conciencia de la enfermedad de esta persona. Desconozco otras razones más poderosas que pudieron existir para desterrarlo de sus progenitores. Pero me parece injusto y poco solidario. Aquí veo la necesidad forzosa de que la enfermera, como persona que pasa con él mas tiempo, se acerque más a el de una manera no tan atemorizada como ha sido nuestro caso, claro que de nuevo se palpa la necesidad de obtener experiencia con personas con este trastorno para llegar a crear esta relación terapéutica.

Estoy segura de que nuestro tono descendente ligado a nuestra timidez o cobardía ha sido percibido por el propio paciente.

Me imagino en su lugar, sintiendo que me temen cuando no tienen nada que temer los que me rodean. Por si no fuera poco, esta persona tenia la honestidad de pedirnos que le aplicásemos la contención mecánica cada vez que sentía que podía agredirnos, y mientras nosotras, seguíamos tratándole, disculpad por la expresión que procedo a utilizar, como al Frankestein de Mary Shelley, como el ser solitario que nadie conoce, y que por lo tanto, nos induce a la actitud lejana y cauta, pero actitud hiriente para la persona que tenemos delante.

\section{La esperanza del insecto}

¡Se me vienen tantas propuestas a la cabeza en cuanto a desarrollar una consulta de enfermería en la unidad por ejemplo, o potenciar la sala de terapias a merced de lo que una paciente me ha comentado hoy! Es decir, la necesidad que me transmitió ha sido: ¿ por qué no organizáis en esa sala, charlas, o escuchamos música o hacemos ejercicio ahí?. Esto se lo comento a la supervisora. Como siempre la falta de intercooperación entre los compañeros de igual o distintas profesiones, y los problemas económicos-burocráticos son el impedimento de estas reformas, tan necesarias considero, para impulsar una labor más profesional y humana.

¿No hay ilusión e iniciativa? ¿Se está a gusto en el terreno de lo estático? ¿Somos puro mecanicismo? Podría seguir infinitamente con más preguntas de estas retóricas que tanto me gusta usar.

Como el insecto que no lucha cuando ha caído en la tela de araña. Pegado, arrastrado a la inmovi- lidad, arrastrado a la perpetuación de ese estado. Así defino yo, parte de la situación que veo ante mis ojos. Por suerte tengo una esperanza depositada en el cambio progresivo aunque no inminente. Pero cambio al fin y al cabo.

\section{Hasta luego, y no hasta nunca}

Hoy es mi último día en la unidad de psiquiatría. A pesar de mi deshabituación y algo de desconcierto que presentaba en los primeros días, ahora me encuentro cómoda, tranquila, sigo sin saber mucho o casi nada del mundo de la psiquiatría, pero almenos, ya sé que me atrae esta disciplina, que las pocas semanas aquí me han servido para ver en qué fallaba a la hora de entrevistar a los pacientes; que es un área de la enfermería que me llama mucho más la atención que otras porque es donde más se hace hincapié en la esfera psíquica y social de la persona.

Y quizá me estoy precipitando o aventurando demasiado, pero la estancia aquí me ha hecho confirmar no sólo que no me he equivocado a la hora de optar por las practicas aquí, sino que me ha hecho descubrir la vertiente de la enfermería que creo que más me motiva en todos los aspectos.

Se me ha hecho breve este periodo. Ha habido momentos con alguna pesadumbre, desmotivación pasajera, sensación de rutina no muy productiva, pero también me he reído, he visto fallos en mi actitud y comportamiento que me han hecho reflexionar, me he sentido culpable por ellos, me he puesto seria y casi déspota con una sola paciente que padecía trastorno limite de la personalidad, pero también aprendí de ella. A veces he sentido agotamiento mental, pero intentado no sucumbir y creo que lo he conseguido, porque he hecho un esfuerzo porque cada día no fuera igual.

Sin embargo, lo que más me ha gustado de estar aquí ha sido el convivir con los pacientes, hablar con ellos, superar esa barrera de la que hablaba los primeros días. No me llevo ninguna experiencia negativa, muy frustrante o traumática con estas personas. Simplemente situaciones, momentos, conversaciones...que han sido de un modo y que me hubieran gustado que se hubieran sucedido de otra manera, pero no me arrepiento de haberlas vivido, pues como ya he repetido en mas de una ocasión, y aunque suene a tópico, me gusta que en mi vida haya errores, espero que no muy 
frecuentes, que de vez en cuando me abran los ojos y me hagan pensar el cómo y porqué de las cosas que hago, pienso, afirmo, etc.

Espero no perder las ganas de trabajar en este campo, porque para mí no es un simple trabajo, es una labor entre personas que interaccionan entre ellas, donde una de las partes generalmente se encuentra sola, triste, aislada, marginada, discriminada, impotente, deprimida, vulnerable, débil, abatida, etc. Y no me gusta darles este tono dramático y pesimista a las personas que padecen cualquier trastorno porque estoy contribuyendo a que la sociedad pueda pensar que no se puede hacer nada por ellos, pero es que desgraciadamente la realidad que viven estas personas es así, una montaña rusa de emociones, estados de ánimo...etc, y es precisamente cuando la sociedad no conoce a este colectivo tan variado cuando no se puede hacer nada.

Así que por esta razón, me doy la enhorabuena por haber elegido este sitio y poder ser consciente ahora de parte de la realidad que viven estas personas, por ser consciente de que existen.

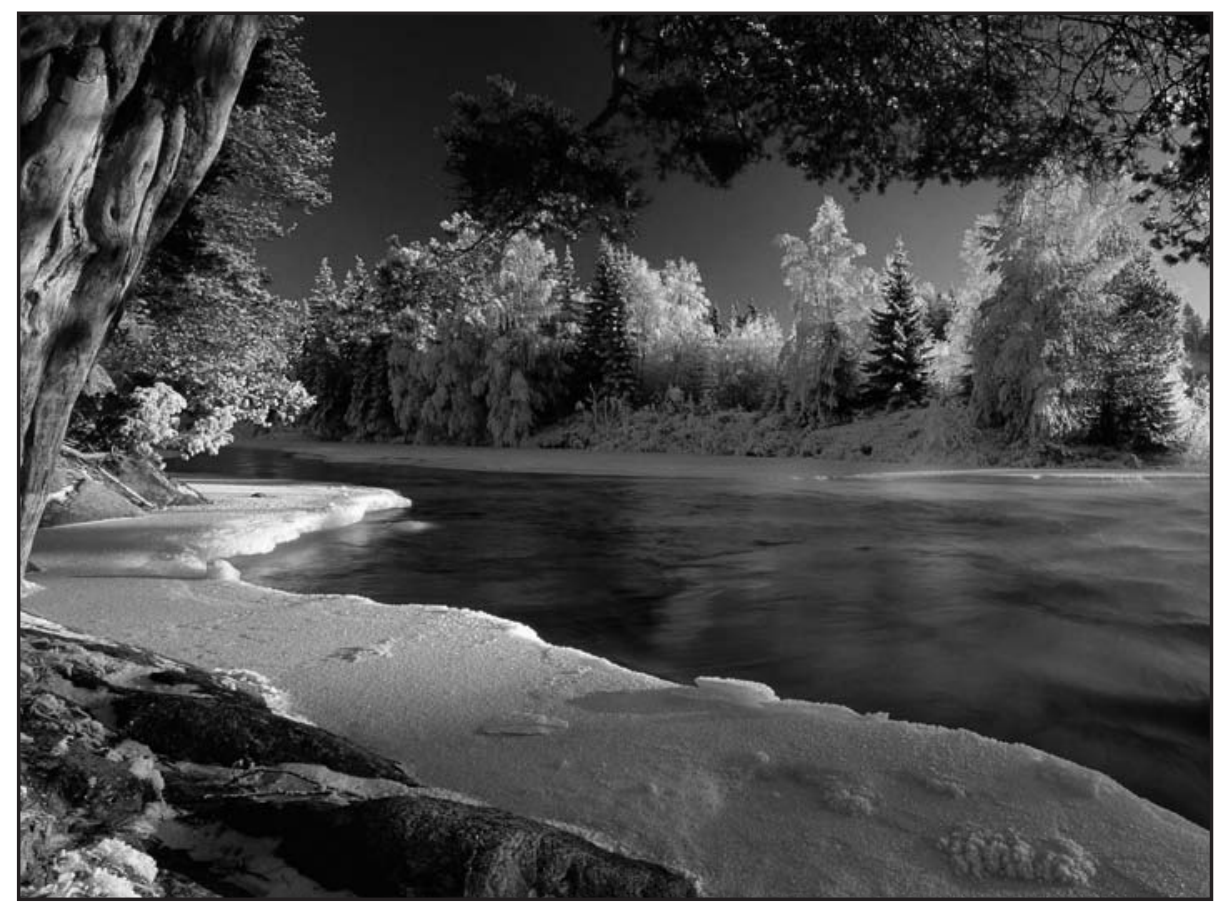

